\title{
ATPENSANDO: JOGO PEDAGÓGICO NO PROCESSO DE ENSINO-APRENDIZAGEM DE BIOQUÍMICA
}

Tamires Fortuna, Amanda Guimarães Azevedo, Tatiane lembo, Carolina Colombelli Pacca, Thomas Eugenio Portes de Almeida, Stephanie Lee Basile Barboza Caseiro, Felipe Colombelli Pacca

Faculdade de Medicina em São José do Rio Preto - FACERES, Curso de Medicina, São José do Rio Preto, SP.

\section{RESUMO}

O processo de ensino de bioquímica para estudantes de medicina que faça uso de ferramentas lúdicas e outras metodologias diversificadas pode ser uma alternativa interessante para promover melhorias no ensino. Assim, o emprego de jogos educativos com uma variedade de propósitos dentro do contexto do aprendizado é uma realidade. Isto porque a ludicidade constrói o saber ao facilitar e dinamizar o sistema educacional vigente. O presente trabalho tem por objetivo apresentar o jogo ATPensando, elaborado para estimular e auxiliar o aprendizado do conteúdo de Bioquímica dos alunos do primeiro semestre do curso de Medicina da Faceres. A metodologia apresentará a descrição do jogo, processo de aplicação e avaliação dos alunos em comparação pré e pós aplicação. Os resultados apresentados demonstram maiores índices de acertos nos testes após a aplicação do jogo. Discute-se a importância do uso de jogos como ferramenta de ensino de bioquímica no curso de medicina.

Palavras-chave: Jogos pedagógicos, Ensino-Aprendizagem, Educação Médica, Ensino de Bioquímica.

\section{ATPTHINKING: PEDAGOGICAL GAME IN TEACHING-LEARNING PROCESS OF BIOCHEMISTRY}

\section{ABSTRACT}

The process of teaching biochemistry to medical students that make use of play tools and other diversified methodologies can be an interesting alternative to promote improvements in teaching. Thus, the use of educational games with a variety of purposes within the context of learning is a reality. This is because playfulness builds knowledge by facilitating and streamlining the current educational system. This work aims to present the game ATPensando, designed to stimulate and aid the learning of the Biochemistry content of the students of the first semester at Faceres Medical School. The methodology will introduce the game description, application process and evaluation of students in a comparison between a pre and post application assessment. The results show an increase in the tests marks after the application of the game. It is discussed the importance of the use of games as a teaching tool of biochemistry in the medical school.

Keywords: Teaching games, Teaching-learning, Medical education, Biochemistry teaching. 


\section{INTRODUÇÃO}

Ao ingressar no ensino superior, o aluno tem contato com um novo cenário, repleto de desafios, principalmente em relação ao vasto conteúdo ao qual será submetido durante os anos de aprendizagem. Esses desafios são necessários para a evolução do aluno e a construção de um bom profissional, ético e competente. Dessa maneira, a educação superior traz ao estudante possibilidades de competência moral que, em teoria, deveriam aperfeiçoar o desenvolvimento do indivíduo. Sobre essa afirmação, no entanto, é preciso esclarecer que competência moral é entendida, a partir de Piaget e Lind, como o processo de reflexão crítica do ser para a contínua exploração de seu desenvolvimento moral $(1,2)$.

No caso do curso de medicina, a complexidade dos desafios do ensino superior pode ser representada nos conteúdos de bioquímica, algo que muitos estudantes consideram complexo e trabalhoso de assimilar, pois correlaciona processos químicos e biológicos complexos (3). Embora o desenvolvimento tecnológico tenha auxiliado muito em questões didáticas e implementado novas formas de estudo, ainda existe dificuldade para muitos professores encontrarem caminhos para garantir o aprendizado de bioquímica. Isso ocorre, de acordo com Fialho, porque aos professores falta motivar os alunos, associando o conteúdo com oportunidades de estudo relacionadas à práticas virtuais ligadas à pesquisas lúdicas pela internet (4).

Porém, ao analisar o processo de motivação a partir de uma perspectiva lúdica, é preciso destacar dois elementos: a imaginação e o jogo. A imaginação, enquanto ferramenta de aceleração do processo de aprendizagem, de acordo com Luria (5), esta ligada à prática ou a um sistema de pensamento lógico-verbal. Assim, imaginar é ato importante para aprender. Nesse contexto, em uma atividade de ensino, utilizar a imaginação é uma possibilidade para estabelecer relações entre conteúdos específicos e teóricos que, em atividades tradicionais e orais, tornar-seiam cansativos e pouco acessíveis aos estudantes.

Alguns autores apontam a importância do jogo no processo de aprendizagem, inclusive destacando o jogo como influência importante para o desenvolvimento moral, social, cognitivo e intelectual (1, 6-9). Assim, é por meio de atividades lúdicas e imaginativas que o ensino de bioquímica pode tornar-se mais ou menos motivante para os alunos. Nesse sentido, organizar, planejar e preparar atividades didáticas é tarefa complexa que exige mais tempo e esforço do docente para a elaboração, implementação e avaliação de atividades. Moretto afirma que ensinar é mediar a construção de significados, buscando enfatizar que oportunizar aos alunos situações de aprendizagem significativa (10). Nesse contexto, o professor precisa organizar o contexto da apresentação do conteúdo aos alunos, de maneira que o acesso às informações seja fácil e significativo. Assim, ao aplicar um método mais dinâmico, é possível além de mudar aulas rotineiras, implementar atividades lúdicas e imaginativas, como jogos, integrando assim as dimensões afetiva, motora e cognitiva do aluno, levando a pessoa que brinca e joga a agir, sentir, pensar, aprender e se desenvolver.

Ao realizar essas atividades, o professor apresenta desafios que se prolongam fora do ambiente de ensino, tornando o assunto mais interessante e proporcionando uma real possibilidade de aprendizagem. É a partir do brincar que a interação de aprendizagem com os pares ocorre. É no conflito durante o jogo que possibilita o surgimento de novas ideias. E é a interação social que possibilita a construção de representações, que, por sua vez, proporcionam aprendizagem e memorização mais efetivas (11). Alves acredita que o brincar ativa inicialmente o tronco cerebral onde mecanismos de sobrevivência são originados, conectando-se e ativando emoções prazerosas que acompanham o ato de brincar/jogar. Essa conexão na vida adulta é realizada em uma série de circunstâncias e, por isso, o ato de brincar ou jogar pode estar relacionado a diversas ações, inclusive com o trabalho (12).

O ensino de conteúdos importantes através das atividades lúdicas, como jogos, proporciona o aprendizado de forma prazerosa e diferenciada, favorecendo assim um meio de 
entendimento mais divertido, dinâmico e atraente. Desse modo, essas atividades diversificadas inserem o aluno como personagem ativo pois ao se deparar com os desafios, o indivíduo sente a necessidade e o desejo de vencê-los, o que provoca uma sensação agradável de interação com o coletivo e mexe com os impulsos competitivos, deixando a aula relativamente mais rápida e interessante, além de deixar de ser uma matéria extenuante para os alunos (13). A diversificação de novos métodos de ensino é necessária para resgatar o interesse pelo aprendizado nos alunos, podendo essa metodologia de atividades lúdicas e interacionais propiciar uma retenção do conhecimento de forma quase que definitiva, não somente uma condição imediata para ser aplicada nas avaliações, mas servindo de base para as outras disciplinas dos próximos anos do curso (11).

Nesse contexto, o objetivo deste estudo é apresentar a aplicação de um jogo pedagógico de ensino de bioquímica para alunos de graduação em medicina, evidenciando a importância do desenvolvimento de atividades lúdicas para a formação completa do estudante.

\section{METODOLOGIA}

O projeto deu-se início logo após a aprovação do Comitê de Ética em Pesquisa da Faculdade Faceres sob parecer consubstanciado $n^{\circ}$ 2.034.014.

O jogo proposto neste estudo foi elaborado por alunos do terceiro período do curso de medicina da Faculdade Faceres, com temática centrada nos conceitos básicos de bioquímica. Para tanto, foram confeccionadas placas de EVA com o nome de enzimas e substratos intermediarias das etapas do metabolismo dos carboidratos, sendo duas placas sobre glicólise, duas sobre ciclo de Krebs e duas de cadeia respiratória, para que os alunos durante o jogo pudessem completar a sequência correta da cadeia reação em mapas conceituais. O jogo foi aplicado em 34 alunos do primeiro período, os quais estavam cursando a disciplina Morfofuncional, que contempla o conteúdo programático sobre metabolismo de carboidratos.

Antes da entrega dos jogos, os alunos responderam a um questionário contendo cinco testes contemplando os principais assuntos de conhecimento considerados chave no processo de compreensão do conteúdo sobre o assunto do estudo. Em seguida, os alunos foram divididos em grupos de cinco a seis pessoas para que pudessem preencher as reações e discutir sobre o tema. Logo após a dinâmica do jogo, o mesmo questionário foi aplicado para análise da eficiência do método pedagógico. Para esta análise, os questionários foram corrigidos e cada aluno recebeu nota nos questionários respondidos antes e após o jogo, valendo de zero a cinco.

Os resultados foram submetidos à estatística descritiva e ao teste Kolmogorov-Smirnov que confirmou a distribuição dos dados como normal. A comparação das notas obtidas antes e depois dos jogos foi realizada por meio do teste $T$ para amostras pareadas com intervalo de confiança de $95 \%$.

Apesar das muitas possibilidades de análises, apresentaremos, nos resultados, apenas duas variáveis, buscando apenas demonstrar a eficácia da atividade lúdica, haja visto que o objetivo do estudo é apresentar a aplicação da atividade e não discutir excessivamente os resultados do questionário utilizado antes e após essa aplicação.

\section{RESULTADOS}

A maior nota possível nas avaliações é de 5 pontos. A nota média antes dos jogos foi de $2,765( \pm 0,955)$ e média depois dos jogos foi de $3,353( \pm 1,152)$ resultando numa diferença entre as médias de $0,588( \pm 1.131)$ que resultou estatisticamente significativa pelo teste $T$ para amostras pareadas com $\mathrm{P}=0,005$ (Figura 1). 


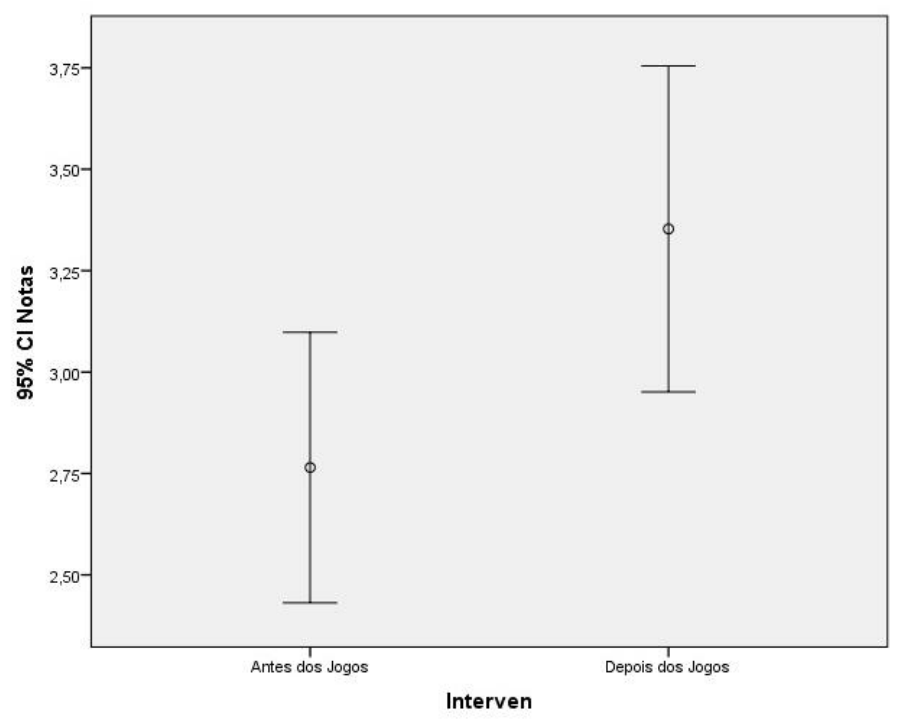

Figura 1. Nota média antes e depois da aplicação dos jogos.

Foram analisadas as porcentagens de acerto de cada questão antes e depois da aplicação dos jogos e observou-se um aumento considerável nas questões 2 ( $45 \%$ antes e $68 \%$ depois) e 3 (48\% antes e $71 \%$ depois) (Figura 2 ).

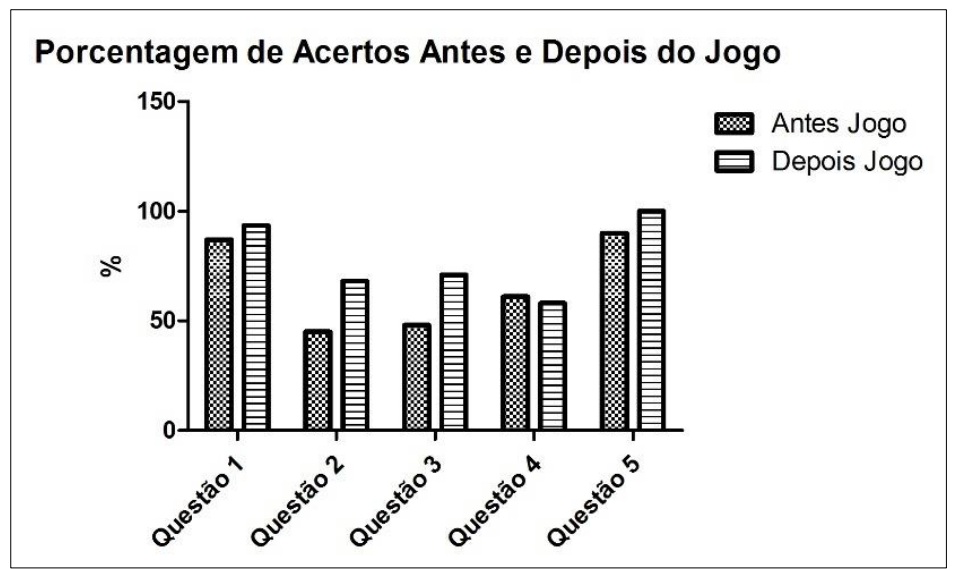

Figura 2. Porcentagem de acertos por questão antes e depois da aplicação dos jogos.

\section{DISCUSSÃO}

ATPensando é um jogo sobre o metabolismo de carboidratos, feito um projeto piloto com placas de EVA, no qual os alunos precisavam completar as cadeias de reações com enzimas ou substratos na ordem adequada através de pequenas placas com os nomes no velcro, sendo duas placas sobre glicólise, duas sobre ciclo de Krebs e duas de cadeia respiratória, sendo que essas placas iriam se alternar entre grupos para todos os grupos de seis alunos vissem e discutissem esses assuntos, de acordo: glicólise -> ciclo de Krebs -> cadeia respiratória.

A estratégia de aprendizagem de bioquímica com ação prática através de jogos além de inovadora proporciona o desenvolvimento de um conhecimento natural do aluno mais duradouro do que a ação de decorar a matéria para fazer uma prova. Machado utilizou um software com animação interativa (14), Leader descreveu um programa baseado na regulação do metabolismo conforme a disponibilidade de nutrientes e a intensidade de exercícios (15), entre outras experiências sobre o tema.

No presente estudo, o jogo foi aplicado em alunos da primeira etapa do curso de medicina, durante a aula de morfofuncional, que engloba o assunto de metabolismo dos carboidratos. Além desta etapa, o curso contempla a Bioquímica novamente no segundo módulo da matéria de 
tutoria que associa assuntos com a morfofuncional para que um mesmo assunto seja visto em diferentes perspectivas na mesma semana.

Dessa maneira, explicita-se, aqui, que as situações de aprendizagem baseadas em atividades lúdicas podem ser potencializadas

\section{CONCLUSÃO}

A formação de um médico é extensa e repleta de desafios, com conteúdos complexos e responsabilidade profissional extremamente pertinente para a sociedade. É importante, então, possibilitar ao graduando as melhores ferramentas, atividades e possibilidades de aprendizagem possíveis. Nesse contexto, é importante que o docente esteja apto para desenvolver novas atividades de ensino e aprendizagem.

Os jogos apresentam potencial imenso para a retenção da informação, de maneira divertida e significativa. Ensinar bioquímica a partir de jogos é possibilitar aos alunos momentos de relação social, intelectual e pedagógicas de uma maneira divertida e funcional. A aplicação do ATPensando foi um dos pontos altos da disciplina morfofuncional e isso fez com que fossem desenvolvidos outros jogos, outras possibilidades, outras atividades lúdicas direcionadas ao ensino de bioquímica. Espera-se que essa atividade sirva de elemento motivador para a criação de novas possibilidades e atividades lúdicas direcionadas ao ensino superior, em especial ao curso de medicina.

\section{REFERÊNCIAS}

1. Piaget J. O juízo moral na criança. São Paulo: Summus; 1994.

2. Lind G. La moral puede enseñarse: manual teórico-práctico de la formación moral y democrática. México: Trillas; 2007.

3. Vasconcellos LC, Bonelli RR. Desenvolvimento de um jogo de tabuleiro destinado a aumentar o nível de aprendizado e interesse do aluno pelo metabolismo energético no ensino médio. XII Encontro Latino Americano de Iniciação Científica e VIII Encontro Latino Americano de Pós-Graduação; Universidade do Vale do Paraíba: Universidade do Vale do Paraíba; 2008. p. 1-4.

4. Fialho NN. OS JOGOS PEDAGÓGICOS COMO FERRAMENTAS DE ENSINO VIII Congresso Nacional de Educação EDUCERE e III Congresso Ibero-Americano sobre violência nas escolas CIAVE; Pontifícia Universidade Católica (PUC) Paraná - Campus Curitiba2008. p. 12298 - 306.

5. Luria AR. Desenvolvimento cognitivo: seus fundamentos culturais e sociais. São Paulo: Ícone; 2008.

6. Château J. O jogo e a criança. São Paulo: Summus; 1987. 142 p.

7. Johnson S. Surpreendente: A televisão e o videogame nos tornam mais inteligentes. Rio de Janeiro: Elsevier; 2005.

8. Jones G. Brincando de matar monstros: por que as crianças precisam de fantasia, videogame e violência de faz-de-conta. São Paulo: Conrad Editora do Brasil; 2004.

9. Huizinga J. Homo ludens. São Paulo: Perspectiva; 1999. 243 p. 
10. Moretto VP. Planejamento: planejando a educação para o desenvolvimento de competências. 8 ed ed. Petrópolis: Vozes; 2012.

11. NOJOSA ACB, BEZERRA CF, LIBERATO MCTC, VASCONCELOS MS. CRIAÇÃO DE JOGOS DIDÁTICOS COMO ESTRATÉGIA NO ENSINO DE BIOQUÍMICA. 49 Congresso Brasileiro de Química; Centro de Eventos do Hotel Plaza São Rafael2009.

12. Alves F. Gamification: Como criar experiências de aprendizagem engajadoras - um guia completo do conceito à prática. 2 ed ed. São Paulo: DVS Editora; 2015.

13. Schwartz G. Brinco, logo aprendo: educação, videogame e moralidade pós-modernas. São Paulo: Paulus; 2014.

14. MACHADO MSR, J; SUGAI, J. K.; ANTÔNIO, R. V.; HEIDRICH, D. N. . Bioquímica através da animação. . Extensio: Revista Eletrônica de Extensão. 2004.

15. Leader DP. The Glasgow Metabolism Suite: undergraduate software for intermediary metabolism. . Biochemical Education. 1999;27:27-30, https://doi.org/10.1016/S0307-4412(98)00162$\underline{9}$. 